\title{
Evaluating Course-Objective Writing Effectiveness: Applying The Comprehensive Bloom Verb List
}

Russell Baker, Jacksonville University

Gina M. Almerico, University of Tampa

Barry Thornton, Jacksonville University

\begin{abstract}
This study is a comparative analysis of the objective writing skills of pre-service teachers to determine the efficacy of utilizing a master verb list based on Bloom's Taxonomy. Students enrolled in a mid-size university were asked to create a set of objectives to measure Bloom's Taxonomy learning outcomes. One group received a master list of verbs categorized through research appropriately into learning levels. The other group received a variety of lists with conflicting verbs in categories. Students who received the master list were better able than their counterparts to write precise, clear and accurate objectives.
\end{abstract}

Keywords: Bloom's Taxonomy, course objectives, pre-service teachers, action verbs, course design, curriculum

\section{INTRODUCTION}

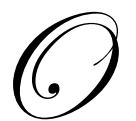

ne of the challenges of working with pre-service teachers is training them in how to compose wellwritten, specifically stated outcomes of student learning. When teacher candidates begin the process of planning for instruction, often they focus on selecting content, developing activities, deciding on methods of delivery, and identifying materials for instructional application. While these components of instructional planning are important, the procedure could be more efficient if they began by clarifying their instructional objectives and using precise language to describe learning outcomes across a continuum of cognitive levels. Students must be taught to identify learning outcomes and can do so by asking how they could describe, in performance terms, what students are like when they have learned what is expected of them (Gronlund, 2004).

Citing objectives as intended learning outcomes of instruction provides a basis for selecting the content, activities, methods, and materials of instruction that are most apt to impact student learning. If students are being asked to comprehend concepts, instructional techniques and materials that enable them to form proper conceptions and eliminate common misconceptions must be planned and implemented. If students are being asked to solve real world problems, projects that require the solving of realistic complex problems must be planned. Clearly stated performance objectives provide a framework for planning the type of instruction needed to bring about desired learning outcomes.

The action verb is the key element in stating the specific learning outcomes that defines student learning. The selection of action verbs is a vital step in the preparation of a useful set of objectives. In choosing action verbs to define learning outcomes, teacher practitioners ask pre-service teacher candidates to consider those that (1) most clearly convey instructional intent and (2) most precisely specify the student performance that is acceptable as evidence that learning has taken place. Unfortunately, action verbs vary widely in their ability to meet both criteria.

Almerico and Baker (2005) analyzed research related to the labeling learning objectives according to Bloom's Taxonomy. In their study they discovered many variations of lists which categorically defined verbs according to Bloom's classification (Airasian, 2001; Bloom's Taxonomy, 2002; Borich \& Tombari, 2004; Chatterji, 
2003; DLRN's Technology Resource Guide, 2002; Gronlund, 2004; Hazari, 2002; Lane, 2002; Lee, 1999; McMillan, 2004; O’Malley \& Pierce, 1996; Objectives in an Outcomes, 2002; Preparing for Clinical, 2002). They learned many of the verbs were assigned to more than one level or category within the hierarchy in a given list. Matters became more convoluted when they found verbs categorized across levels of the taxonomy in different lists. When educators ask their students to choose action verbs to clearly convey instructional intent, precisely specify student performance, and pinpoint the level of cognition addressed, conflicting lists can lead to frustration and confusion. As a result of the analysis, Almerico and Baker developed a master list of action verbs in each ofx Bloom's Taxonomy's six levels (http://users.ju.edu/rbaker1/BloomVerbList.htm).

\section{COMPARATIVE ANALYSIS}

A comparison of undergraduate pre-service teachers was conducted to determine if the quality of their written objectives increased in the ability to (1) clearly convey instructional intent, (2) precisely specify student performance considered acceptable as evidence of learning, and (3) precisely describe learning outcomes across the six Bloom's Taxonomy levels after having received and used the Almerico and Baker (2005) illustrative verb list. Students participating in this study were juniors and seniors who had been accepted into the teacher preparation program at a mid-size university. The study took place over two academic years. Students were enrolled in an educational assessment class and were asked to work in small groups to complete an assignment where they were asked to complete the following tasks:

1. Watch a video of an exemplary teacher teaching an elementary-level math lesson,

2. Write a summary of the lesson,

3. Construct one objective for each level of Bloom's Taxonomy for the lesson,

4. Develop two assessment strategies which can be used to ascertain student acquisition of each objective,

5. Show the lesson to peers and share their work.

The research question in this study was, if pre-service teachers are provided Almerico and Baker's illustrative verb list, they will be able to apply what they have learned from the database and write objectives that more clearly convey instructional intent, are more precise, and better describe learning outcomes across taxonomy levels. Both groups were instructed in the same manner by their professor in objective writing. Both groups used the same videos, had the same set of written directions for completing this assignment, and both had the same scoring rubric which was used to evaluate their work. In this study the independent variable or the one variable that was changed to test the hypothesis was the illustrative verb list. The first group, the control group, participated during the first of the two academic years of the study. These students were asked to complete this assignment without the benefit of the Almerico and Baker master verb list. Instead, these students were given multiple lists (copies of the lists mentioned above). The second group, the experimental group, participated during the second academic year of the study. The only list of verbs provided to this group was the Almerico and Baker list. The maximum number of points students could earn on this assignment was 32. Objectives were judged across a continuum; moving from the incomplete or incorrect ability to convey instructional intent, specify student performance considered acceptable as evidence of learning and identify appropriate cognitive level to a precise description of each of the aforementioned criteria.

\section{HYPOTHESIS}

$\mathbf{H}_{\mathbf{0}}: \quad \mu 1<=\mu 2$, the intervention treatment did not make experimental group scores higher than the control group scores.

Ha: $\quad \mu 1>=\mu 2$, The intervention treatment did make experimental group scores group scores.

higher than the control 


\section{DATA ANALYSIS}

An analysis of the data was conducted pursuant to the following:

Group 1 = experimental group

Group 2 = control group

Intervention treatment - students in the experimental group were provided access to the aforementioned Blooms Taxonomy verb list.

The evaluation procedure used is a one-tail t-test for comparing two independent means with a level of significance of $.05(\alpha=.05)$ pursuant to the following formula:

$$
\begin{aligned}
& t=\frac{X_{1}-X_{2}}{\sqrt{S_{P}^{2}\left(1 / n+1 / n_{2}\right)}} \\
& S_{P}^{2}=\frac{\left(n_{1}-1\right) S_{1}^{2}+\left(n_{2}-1\right) S_{2}^{2}}{n_{1}+n_{2}-2}
\end{aligned}
$$

\begin{tabular}{|c|c|c|c|c|c|c|c|c|c|c|}
\hline \multicolumn{11}{|c|}{ Control Group N=6 } \\
\hline Group \#> & 1 & 2 & 3 & 4 & 5 & 6 & X1 & S1 & $\mathrm{S1}^{2}$ & $\mathbf{n}$ \\
\hline Group Score> & 3 & 2 & 5 & 1 & 4.5 & 4 & 3.250 & 1.541 & 2.375 & 6 \\
\hline \multicolumn{11}{|c|}{ Experimental Group $\mathrm{N}=6$} \\
\hline Group \#> & 1 & 2 & 3 & 4 & 5 & 6 & $\mathrm{X} 2$ & S2 & $\mathbf{S 2}^{2}$ & $\mathbf{n}$ \\
\hline Group Score> & 4.5 & 6 & 5 & 5.5 & 6 & 5 & 5.333 & 0.606 & 0.367 & 6 \\
\hline $\mathbf{S}_{\mathbf{P}}^{2}>$ & \multicolumn{10}{|c|}{1.370833333} \\
\hline test $\mathrm{t}>$ & \multicolumn{10}{|c|}{3.081960455} \\
\hline df $>$ & \multicolumn{2}{|c|}{$\mathrm{n} 1+\mathrm{n} 2-2=$} & 10 & & & & & & & \\
\hline Critical Value > & & 1.812 & & & & & & & & \\
\hline tdist (probability)> & & 0.006 & & & & & & & & \\
\hline
\end{tabular}

Table 1: Summary data and statistical analysis

As indicated in Table 1, the test $t$ statistic result is 3.0819. Using a degrees-of-freedom value of 10, the critical value for the test is 1.812 . The tdist value of .006 indicates a less than one percent probability that this result was from a factor other than the intervention treatment. Therefore, the null hypothesis is rejected. The sample evidence suggests the intervention treatment was effective in raising the objective-writing scores.

Students in the control group consistently scored lower point values in their ability to write objectives. One group was unable develop a single objective which accurately met assignment criteria. They were unable to accurately identify verbs that describe learning outcomes by cognitive ability. Another group earned demonstrated trouble with creating higher-level objectives. A third group lost points with knowledge, synthesis and evaluation level objectives. They could not determine which verbs best stated learning outcomes at these levels. Of the six control groups studied none wrote objectives that met all assigned criteria. In contrast, student groups which were in the experimental group, those with the Almerico and Baker illustrative verb list, consistently wrote objectives which met assigned criteria. 


\section{CONCLUSION}

Based on an analysis of objectives written by pre-service teachers before and after receiving and using the master verb list, and the observation of student scores, it was concluded the Illustrative Verbs Corresponding to the Cognitive Levels of Bloom's Taxonomy list provided students with a basis upon which to build effective instructional objectives. Students in the experimental group were able to use the categorized verbs to clearly describe what they wanted their students to learn or be able to do following their instruction. They were better able than their cohorts to describe in very precise terms, including an accurate labeling of cognitive processing, what students were to accomplish as a result of instruction (Mertler, 2003).

\section{REFERENCES}

1. (2002) Bloom's Taxonomy (On-line). Available: www.coun.uvic.ca/learn/program/hndouts/bloom.html.

2. (2002) Distance Learning (On-line). Available: http://distancelearn.about.com/mbody.htm.

3. (2002) DLRN's Technology Resource Guide (On-line). Available: www.dlrn.org/lybrary/dl/guide4.html.

4. (2002) Objectives in an Outcomes Focused Learning Environment (On-line). Available: www.eddept.wa.edu.au/cip/learntech/res/res2.htm.

5. (2002) Preparing for Clinical Teaching (On-line). Available: www.utexas.edu/phamarcy/general/experimental/practitioner/effective/prep.html.

6. $\quad$ Airasian, P.W. (2001). Classroom assessment: Concepts and applications (4 ${ }^{\text {th }}$ ed.). Boston: Mc Graw Hill.

7. Almerico, G.M. \& Baker, R. (2005). Bloom's Taxonomy illustrative verbs: Developing a comprehensive list for educator use. EMontage, Journal of the Florida Association of Teacher Educators.

8. Bloom, B., Englehart, M.D., Furst, E.J., Hill, W.H., \& Krathwohl, D.R. (1956). Taxomony of educational objectives: Handbook I, cognitive domain. New York: David McKay.

9. Borich, G.D. \& Tombari, M.L. (2004). Educational assessment for the elementary and middle school classroom ( ${ }^{\text {nd }}$ ed.). Upper Saddle River, NJ: Pearson.

10. Chatterji, M. (2003). Designing and using tools for educational assessment. Boston: Allyn and Bacon.

11. Granello, D.H. (2001). Promoting cognitive complexity in graduate written work: Using Bloom's Taxonomy to improve literature reviews. Counselor Education and Supervision, 40, 292-307.

12. Gronlund, N.E. (2003). Assessment of student achievement ( $7^{\text {th }}$ ed.). Boston: Allyn and Bacon.

13. Gronlund, N.E. (2004). Writing instructional objectives for teaching and assessment $\left(7^{\text {th }}\right.$ ed.). Upper Saddle River, NJ: Pearson.

14. Hazari, S. (2002) Online Testing Methods for Web Courses (On-line). Available: sunil.umd.edu/documents/assmnt/onlinetest.htm.

15. Lane, C. (2002) Bloom's Taxonomy of Learning (On-line). Available: www.uis.edu/ jenkins/Bloom.htm.

16. Lee, V.S. (1999). Benjamin Bloom's taxonomy on cognitive behaviors. The National Teaching and Learning Forum Newsletter, 8, 62-66.

17. McMillan, J.H. (2004). Classroom assessment: Principles and practice for effective instruction ( $3^{\text {rd }}$ ed.). Boston: Pearson.

18. Mertler, C.A. (2003). Classroom assessment: A practical guide for educators. Los Angeles, CA: Pyrczak Publishers.

19. O’Malley, J. M. \& Pierce, L.V. (1996). Authentic assessment for English language learners: Practical approaches for teachers. United States: Addison-Wesley Publishing.

\section{Appendix}

Table 1

Illustrative Verbs Corresponding to the Cognitive Levels of Bloom's Taxonomy is available at: http://users.ju.edu/rbaker1/BloomVerbList.htm. 